\title{
DISTRIBUSI SPASIAL PENDERITA MALARIA DI DISTRIK SENTANI TIMUR KABUPATEN JAYAPURA
}

\author{
Henny Sesanti Budi Hastuty ${ }^{(1)}$ dan Denik Wahyu Setyowati ${ }^{(2)}$ \\ ${ }^{1,2}$ Sanitasi, Politeknik Kesehatan Kemenkes Jayapura \\ 1,2,J1. Padang Bulan II Abepura Kota Jayapura Kode Pos 99351 \\ E-mail : hennysesanti@gmail.com ${ }^{1)}$,denikwahyu63@gmail.com ${ }^{2)}$
}

\begin{abstract}
ABSTRAK
Papua merupakan daerah endemik malaria dan sebagai penyumbang kasus terbesar di Indonesia yaitu sebesar $79 \%$ kasus. API (Annual Parasite Incidence) Kabupaten Jayapura termasuk dalam tiga kabupaten dengan API tertinggi di Indonesia. Penelitian ini bertujuan untuk menggambarkan distribusi spasial epidemiologi penderita malaria di Kampung Nolokla Distrik Sentani Timur tahun 2019. Jenis penelitian deskriptif dengan rancangan penelitian eksploratif, pendekatan observasi dan survei dengan Sistem Informasi Geografi (SIG). Populasi adalah seluruh penderita malaria yang beralamat di Kampung Nolokla yang tercatat pada register rawat jalan Puskesmas Harapan Distrik Sentani Timur bulan Januari sampai Maret 2019. Hasil penelitian menunjukkan jumlah penderita malaria adalah sejumlah 290 orang. Berdasarkan kelompok kelompok umur tertinggi pada 15-64 tahun yaitu (52,1\%), jenis kelamin laki-laki (53\%), waktu kejadian malaria tertinggi pada bulan Maret (40,4\%), tempat tinggal di RW 3 (37,9\%). Peta distribusi spasial penderita malaria pada bulan Februari hingga Maret tersebar merata di seluruh RW dengan jumlah keseluruhan sebanyak 98 titik penderita malaria dan sebagian besar penderita malaria di RW 3 dengan jumlah sebanyak 37 orang. Kesimpulan, bahwa distribusi spasial epidemiologi penderita malaria di Kampung Nolokla Distrik Sentani Timur terletak di RW 3, letak rumah penderita malaria berada di pinggiran hutan, rawa -rawa, terdapat kubangan dan genangan air sehingga berpotensi menjadi tempat perindukan larva Anopheles sp.
\end{abstract}

Kata Kunci: Distribusi Penderita, Distribusi Spasial, Epidemiologi Malaria, Penderita Malaria, Sistem Informasi

\section{PENDAHULUAN}

Malaria hingga saat ini masih menjadi masalah kesehatan di Indonesia tercatat pada tahun 2018 terjadi sebanyak 222.085 kasus. Penyumbang kasus malaria tertinggi berasal dari lima provinsi di bagian Timur Indonesia, yaitu Provinsi Papua, Papua Barat, Maluku, Maluku Utara dan Nusa Tenggara Timur. Provinsi Papua merupakan provinsi dengan jumlah kasus tertinggi di Indonesia dengan jumlah 176.070 kasus. Situasi malaria di Kabupaten Jayapura pada tahun 2018, angka API > 100 bersama dengan Kabupaten Keerom, Sarmi,Mimika dan Boven Digoel. Meskipun angka kematian akibat malaria mengalami penurunan dari tahun ke tahun, namun penularannya masih cukup tinggi sehingga memerlukan upaya-upaya pengendalian yang efektif agar cita-cita eliminasi malaria Indonesia dapat tercapai di tahun 2030 (Kemenkes RI,2018).

Malaria merupakan salah satu penyakit yang ditularkan oleh Anopheles sp betina. Malaria disebabkan oleh parasit yang hidup di dalam tubuh Anopheles sp betina, yang masuk ke dalam pembuluh darah manusia saat nyamuk Anopheles sp betina menghisap darah manusia. Dikenal ada empat jenis Plasmodium yang dapat menyebabkan malaria, yaitu Plasmodium vivax, Plasmodium falciparum, Plasmodium malariae, dan Plasmodium ovale. Anopheles sp sebagai penularan malaria tersebar di seluruh Indonesia, dikenal ada 24 spesies yang dapat menularkan malaria, sedangkan di Papua terdapat empat spesies yang dapat menularkan malaria, yaitu Anopheles koliensis, Anopheles punctulatus, Anopheles bancrofti dan Anopheles farauti (Balitbang Biomedis, 2015).

Menurut epidemiologi penyakit, penyebaran (distribution) penyakit malaria dapat dideskripsikan menurut orang (person), tempat (place), dan waktu (time). Studi tentang distribusi sangat bermanfaat dalam banyak hal, di antaranya dapat digunakan untuk mengetahui besarnya beban penyakit (disease burden) pada populasi tertentu, menentukan diagnosis masalah kesehatan pada populasi, dan menetapkan prioritas masalah kesehatan (Arsunan,A.A, 2012). Berdasarkan data dari Kemenkes RI tahun 2018, tercatat bahwa sebagian besar penderita malaria pada usia produktif yaitu 15-64 tahun sebesar 57\%, sedangkan tercatat penderita terendah pada golongan usia 0-11 bulan dan $>64$ tahun, masing-masing tercatat sebesar 2\%. Salah satu kelompok yang rentan jika terkena malaria adalah ibu hamil, pada tahun 2018 tercatat sebanyak $1769 \mathrm{ibu}$ hamil terkena malaria dan terbanyak berasal dari Papua. Jika dibandingkan proporsi kejadian malaria pada ibu hamil dibandingkan dengan seluruh kejadian malaria yaitu sebesar 0,8\% (Kemenkes RI,2018). Hal ini membuktikan bahwa pentingnya memetakan kejadian malaria berdasarkan variabel orang, sehingga 
memudahkan dalam penanganan malaria utamanya di daerah-daerah endemik.

Untuk menurunkan angka API di Indonesia maka pemerintah telah menetapkan melalui Keputusan Menteri Kesehatan No.293/MENKES/SK/IV/2009 bahwa upaya pengendalian malaria dilakukan dalam rangka eliminasi malaria di Indonesia pada tahun 2030. Eliminasi malaria dilakukan melalui program Sustainable Development Goals (SDGs) dengan menggunakan Sistem Informasi Geografis (SIG) yang merupakan sistem informasi yang digunakan untuk memasukkan, menyimpan, mengolah, menganalisis dan menghasilkan data mereferensi geografis atau data geospatial, selain itu juga SIG menangani data spasial. Data spasial adalah data yang memiliki gambaran wilayah yang terdapat di permukaan bumi dan memiliki sistem koordinat tertentu. SIG bermanfaat dalam mendukung pengambilan keputusan dalam perencanaan dan pengelolaan penggunaan lahan, sumber daya alam, lingkungan transportasi, fasilitas kota, dan pelayanan umum lainnya termasuk dalam bidang kesehatan untuk mendukung sistem surveillance penyakit malaria (Cahyati \& Lukman, 2015 ; Hutrianto \& Syakti, 2019)

Sistem Informasi Geografi (SIG) memanipulasi data geografi dalam bentuk visualisasi peta sehingga jika digunakan dalam bidang kesehatan dapat memudahkan petugas kesehatan dalam melakukan analisis masalah di wilayah kerjanya. Penggunaan SIG dalam memetakan tempat sebaran penderita malaria akan memberikan gambaran tentang sebaran lokasi penderita malaria, yang kemudian dapat dianalisis pola penyebaran malaria di suatu wilayah tertentu. Agar penyebaran penyakit malaria dapat terkontrol dan tertanggulangi maka diperlukan program pemerintah dan informasi yang terkait dengan penderita malaria itu sendiri. Kebutuhan informasi penderita malaria menjadi sangat penting agar program pemerintah yang akan diluncurkan berbasis data yang kuat

Kampung Nolokla adalah salah satu kampung yang berada Distrik Sentani Timur, Kabupaten Jayapura, Provinsi Papua. Data yang diperoleh dari Puskesmas Harapan diketahui bahwa jumlah penduduk di Kampung Nolokla sebanyak 2.481 orang dengan angka API pada tahun 2018 yaitu 0,26 per 1000 penduduk. Tingginya angka API disebabkan karena adanya lingkungan fisik luar rumah yang kurang dijaga kebersihannya sehingga berpotensi menjadi tempat perindukan seperti selokan, kubangan, kolam, bekas injakan ban, barang bekas, dan yang menjadi dominan tempat perindukan positif larva nyamuk Anopheles sp terdapat di tiga (3) tempat yaitu kubangan, bekas injakan ban dan barang bekas (Hastuty \& Natalia, 2020). Penelitian distribusi spasial penderita malaria di Kabupaten Jayapura khususnya di wilayah kerja Puskesmas Harapan belum pernah dilakukan, sehingga dengan mengetahui distribusi penderita malaria dapat diketahui lokasi mana sajakah yang paling banyak menjadi penyumbang kasus malaria sehingga diharapkan akan mempermudah penanganan malaria pada lokasi tersebut, baik pada penderita malaria itu sendiri maupun terhadap lingkungan sekitar rumah penderita malaria, sehingga penanganan malaria dapat komprehensif.

\section{RUANG LINGKUP}

Pengetahuan terhadap distribusi penderita malaria berdasarkan kelompok umur, jenis kelamin, sangat dibutuhkan untuk mengetahui kelompok masyarakat yang rentan terhadap penularan malaria, dan pengetahuan tentang waktu kejadian, dibutuhkan untuk mengetahui kapan waktu terjadinya penularan malaria tertinggi sehingga dapat dilakukan antisipasi untuk mencegah lonjakan kasus malaria.

Penggambaran distribusi spasial penderita malaria berperan penting dalam menentukan lokasi sasaran intervensi, karena penularan malaria bukan hanya ditentukan oleh faktor Host (orang), namun juga ditentukan oleh Environment (lingkungan) yang mendukung keberadaan Agent (Plasmodium).

Hasil penelitian ini akan membantu memberikan gambaran yang komprehensif mengenai kelompok masyarakat mana yang rentan terhadap penularan malaria waktu penularan tertinggi, dan sebaran penderita malaria sehingga dapat menentukan jenis intervensi yang tepat terhadap Host, Agent, dan Environment dalam rangka upaya menurunkan kasus malaria.

\section{BAHAN DAN METODE}

Penelitian ini adalah penelitian observational dengan rancangan penelitian eksploratif, menggunakan pendekatan observasi dengan buku register rawat jalan Puksemas untuk mengetahui distribusi (penyebaran) penderita malaria menurut umur, jenis kelamin, tempat tinggal, dan pendekatan survei dengan sistem informasi geografi (SIG) untuk menggambarkan distribusi spasial/pemetaan penderita malaria. Lokasi penelitian di Kampung Nolokla Distrik Sentani Timur. Waktu penelitian dilakukan pada bulan Mei Tahun 2019. Subjek dalam penelitian ini adalah seluruh penderita malaria yang beralamat di Kampung Nolokla dan tercatat pada register rawat jalan Puskesmas Harapan Distrik Sentani Timur pada bulan Januari hingga Maret 2019 yaitu 290 orang. Data lokasi tempat tinggal pasien diperoleh dari buku register rawat jalan malaria Puskesmas Harapan Distrik Sentani Timur.

Peneliti melakukan pencatatan koordinat rumah penderita dengan melakukan kunjungan ke rumah pasien secara langsung. Data koordinat yang telah diperoleh dari hasil survei selanjutnya akan dibuat dalam bentuk peta digital menggunakan aplikasi Arc Gis 10.1. Selanjutnya data yang diperoleh ditampilkan dalam bentuk tabel, peta, dan dijelaskan untuk menggambarkan distribusi spasial penderita malaria Kampung Nolokla wilayah kerja Puskesmas Harapan. 


\section{PEMBAHASAN}

Penelitian dilakukan terhadap 290 responden, hasil meliputi penggambaran distribusi penderita malaria berdasarkan umur, jenis kelamin, tempat tinggal, waktu kejadian dan distribusi spasial penderita malaria.

\subsection{Distribusi Penderita Malaria Berdasarkan Umur}

Data penderita malaria yang diperoleh dari register Puskesmas Harapan pada bulan Januari hingga Maret tahun 2019 diperoleh gambaran distribusi penderita malaria berdasarkan umur pada tabel 1 .

Tabel 1. Distribusi Penderita Malaria Berdasarkan Umur Di Kampung Nolokla Distrik Sentani Timur

\begin{tabular}{ccc}
\hline $\begin{array}{c}\text { Jenis } \\
\text { Kelamin }\end{array}$ & $\begin{array}{c}\text { Frekuensi } \\
(\mathrm{f})\end{array}$ & $\begin{array}{c}\text { Persentase } \\
(\%)\end{array}$ \\
\hline Laki -laki & 136 & 47 \\
Perempuan & 154 & 53 \\
\hline Jumlah & $\mathbf{2 9 0}$ & $\mathbf{1 0 0}$ \\
\hline
\end{tabular}

Tabel 1 menunjukkan bahwa penderita malaria di Kampung Nolokla Distrik Sentani Timur berdasarkan kelompok umur tertinggi pada umur 15-64 tahun yaitu 151 orang $(52,1 \%)$ dan kelompok umur terendah $>64$ tahun yaitu 3 orang (1\%)

\subsection{Distribusi Penderita Malaria Berdasarkan Jenis Kelamin}

Data penderita malaria yang diperoleh dari register Puskesmas Harapan pada bulan Januari hingga Maret tahun 2019 diperoleh gambaran distribusi penderita malaria berdasarkan jenis kelamin pada tabel 2 .

Tabel 2. Distribusi Penderita Malaria Berdasarkan Jenis Kelamin Di Kampung Nolokla Distrik Sentani Timur

\begin{tabular}{ccc}
\hline $\begin{array}{c}\text { Umur } \\
\text { (Tahun) }\end{array}$ & $\begin{array}{c}\text { Frekuensi } \\
(\mathrm{f})\end{array}$ & $\begin{array}{c}\text { Persentase } \\
(\%)\end{array}$ \\
\hline$<1$ & 7 & 2,4 \\
$1-4$ & 29 & 10 \\
$5-9$ & 44 & 15,2 \\
$10-14$ & 56 & 19,3 \\
$15-64$ & 151 & 52,1 \\
$>64$ & 3 & 1 \\
\hline Jumlah & $\mathbf{2 9 0}$ & $\mathbf{1 0 0}$ \\
\hline
\end{tabular}

Tabel 2 menunjukkan bahwa penderita malaria di Kampung Nolokla Distrik Sentani Timur berdasarkan jenis kelamin hampir merata untuk kedua jenis kelamin. Pada laki -laki yaitu 136 orang (47\%) dan perempuan yaitu 154 orang $(53 \%)$

\subsection{Distribusi Penderita Malaria Berdasarkan Tempat Tinggal}

Data penderita malaria yang diperoleh dari register Puskesmas Harapan pada bulan Januari hingga Maret tahun 2019 diperoleh gambaran distribusi penderita malaria berdasarkan tempat tinggal pada tabel 3 .

Tabel 3. Distribusi Penderita Malaria Berdasarkan Tempat Tinggal Di Kampung Nolokla Distrik Sentani Timur

\begin{tabular}{|c|c|c|c|c|c|c|c|c|c|}
\hline \multirow{3}{*}{$\begin{array}{c}\text { Tempat Tinggal } \\
(\mathrm{RW})\end{array}$} & \multicolumn{6}{|c|}{ Frekuensi } & \multirow{2}{*}{\multicolumn{2}{|c|}{$\begin{array}{l}\text { Jumlah } \\
\text { Frekuensi }\end{array}$}} & \multirow{3}{*}{ Persentase Rgs } \\
\hline & \multicolumn{2}{|c|}{$\mathrm{B} \ln 1$} & \multicolumn{2}{|c|}{$\mathrm{B} \ln 2$} & \multicolumn{2}{|c|}{$\mathrm{B} \ln 3$} & & & \\
\hline & Rgs & AT & Rgs & AT & Rgs & AT & Rgs & AT & \\
\hline 1 & 8 & 0 & 14 & 8 & 18 & 9 & 39 & 17 & 13,5 \\
\hline 2 & 7 & 0 & 15 & 5 & 19 & 8 & 41 & 13 & 14,1 \\
\hline 3 & 24 & 0 & 38 & 17 & 46 & 20 & 110 & 37 & 37,9 \\
\hline 4 & 14 & 0 & 20 & 11 & 15 & 6 & 49 & 17 & 16,9 \\
\hline 5 & 12 & 0 & 21 & 7 & 18 & 7 & 51 & 14 & 17,6 \\
\hline Jumlah & 65 & $\mathbf{0}$ & 108 & 47 & 117 & 51 & 290 & 98 & 100 \\
\hline
\end{tabular}

Tabel 3 menunjukkan bahwa penderita malaria di Kampung Nolokla Distrik Sentani Timur pada bulan Januari hingga Maret tahun 2019 berdasarkan tempat tinggal sangat berbeda antara register yang tercatat oleh Puskesmas Harapan yaitu 290 penderita malaria, dengan hasil survei lapangan yaitu 98 penderita malaria. Hal ini disebabkan pada bulan Januari alamat yang tercatat di register Puskesmas Harapan tidak lengkap sehingga sulit ditelusuri, pada bulan Februari dan Maret penderita malaria yang sudah pindah bahkan yang berobat di Puskesmas Harapan bukan tinggal di Kampung Nolokla, tetapi penderita menggunakan kartu berobat menggunakan kartu berobat dari keluarga yang tinggal di Kampung Nolokla. Dapat dilihat dari hasil di atas bahwa penderita malaria di Kampung Nolokla Distrik Sentani Timur tahun 2019 berdasarkan tempat tinggal yang 
tercatat di register Puskesmas Harapan yang tertinggi pada RW 3 yaitu 110 orang $(37,9 \%)$.

\subsection{Distribusi Penderita Malaria Berdasarkan Waktu}

Data penderita malaria yang diperoleh dari register Puskesmas Harapan pada bulan Januari hingga Maret tahun 2019 diperoleh penggambaran distribusi penderita malaria berdasarkan waktu pada tabel 4 .

Tabel.4 Distribusi Penderita Malaria Berdasarkan Waktu Di Kampung Nolokla Distrik Sentani Timur

\begin{tabular}{ccc}
\hline Waktu & Frekuensi (f) & $\begin{array}{c}\text { Persentase } \\
(\%)\end{array}$ \\
\hline Januari & 65 & 22,4 \\
Februari & 108 & 37,2 \\
Maret & 117 & 40,4 \\
\hline Jumlah & $\mathbf{2 9 0}$ & $\mathbf{1 0 0}$ \\
\hline
\end{tabular}

Tabel 4 menunjukkan bahwa penderita malaria di Kampung Nolokla Distrik Sentani Timur berdasarkan waktu tertinggi pada bulan Maret yaitu 117 orang $(40,4 \%)$ dan waktu terendah pada bulan Januari 65 orang $(22,4 \%)$

\subsection{Distribusi Spasial Penderita Malaria}

Data penderita malaria yang diperoleh dari survei lapangan menggunakan GPS sebagai panduan arah pengumpulan data pada bulan Februari hingga Maret tahun 2019 diperoleh karakteristik penderita malaria berdasarkan distribusi spasial penderita malaria pada gambar 1 .

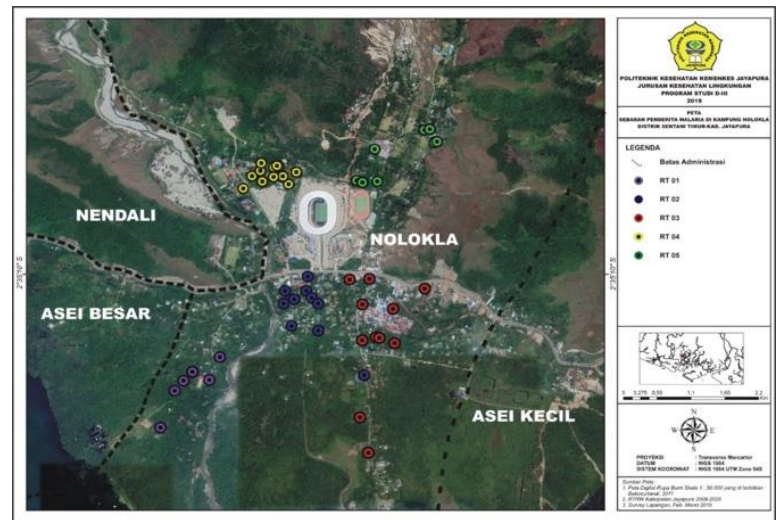

Gambar 1. Peta Distribusi Spasial Penderita Malaria di Kampung Nolokla Distrik Sentani Timur Bulan Februari- Maret Tahun 2019

Gambar 1 menunjukkan bahwa penderita malaria di Kampung Nolokla Distrik Sentani Timur berdasarkan peta distribusi spasial penderita malaria pada bulan Februari hingga Maret pada RW 1 yaitu 17 titik penderita malaria, RW 2 yaitu 13 titik penderita malaria,
RW 3 yaitu 37 titik penderita malaria, RW 4 yaitu 17 titik penderita malaria dan RW 5 yaitu 14 titik penderita malaria. Dapat dilihat dari hasil di atas bahwa penderita malaria di Kampung Nolokla Distrik Sentani Timur tahun 2019 berdasarkan peta distribusi spasial penderita malaria tertinggi pada RW 3 yaitu 37 titik penderita malaria dan terendah pada RW 2 yaitu 13 titik penderita malaria.

Kampung Nolokla adalah salah satu kampung yang yang terletak di Distrik Sentani Timur, Kabupaten Jayapura dengan terbagi menjadi 5 RW dan wilayahnya yang strategis dan merupakan lokasi stadion utama PON XX. Kondisi geografi Kampung Nolokla didominasi oleh area gunung, bukit, dan pemukiman penduduk, danau, halaman yang terdapat rawa-rawa yang langsung terkena sinar matahari sehingga berpotensi menjadi tempat perindukan nyamuk Anopheles $s p$ dan mudah terjadi penularan malaria. Kegiatan pembangunan stadion utama PON XX membutuhkan banyak tenaga kerja yang berasal dari luar Papua. Keberadaan para pekerja yang belum memiliki daya tahan terhadap malaria, akan menambah angka kasus malaria di Puskesmas Harapan.

Penentuan kejadian karakteristik penderita malaria berdasarkan data positif malaria menurut kelompok umur, jenis kelamin, tempat tinggal dan waktu yang diperoleh dari register Puskesmas Harapan pada bulan Januari hingga Maret tahun 2019 di Kampung Nolokla Distrik Sentani Timur yaitu 290 orang. Saat penelitian dilakukan dengan survei lapangan menggunakan GPS dan membawa data penderita malaria dari register Puskesmas Harapan berdasarkan tempat tinggal, namun datanya berbeda yaitu 98 Orang. Hal ini disebabkan pada bulan Januari alamat yang tercatat di register Puskesmas Harapan tidak lengkap sehingga sulit ditelusuri, pada bulan Februari dan Maret penderita malaria yang sudah pindah bahkan yang berobat di Puskesmas Harapan bukan tinggal di Kampung Nolokla, tetapi penderita menggunakan kartu berobat menggunakan kartu berobat dari keluarga yang tinggal di Kampung Nolokla.

Penderita malaria di Kampung Nolokla Distrik Sentani Timur berdasarkan kelompok umur tertinggi pada umur 15-64 tahun yaitu 151 orang $(52,1 \%)$ dan kelompok umur terendah $>64$ tahun yaitu 3 orang (1\%). Hal ini menunjukkan semakin produktif usia seseorang peluang terkena malaria semakin besar, hal ini berkaitan dengan perilaku dan kebiasaan orang yang produktif melakukan aktivitas di luar rumah pada malam hari sebagai mana teori yang menyatakan kebiasaan untuk berada di luar rumah sampai larut malam, di mana vektornya bersifat eksofilik dan eksofagik akan memudahkan gigitan nyamuk Anopheles sp. Kebiasaan penduduk berada di luar rumah pada malam hari dan juga tidak berpakaian berhubungan kejadian malaria, hal ini sesuai dengan penelitian Suwito dkk, (2010), bahwa penularan malaria tidak terlepas dari aktivitas masyarakat itu sendiri.

Berdasarkan jenis kelamin, penderita malaria di Kampung Nolokla Distrik Sentani Timur distribusi 
hampir merata untuk kedua jenis kelamin, pada laki-laki yaitu 136 orang (47\%) dan perempuan yaitu 154 orang (53\%). Laki-laki banyak menderita malaria karena nyamuk Anopheles sp (nyamuk penularan malaria) mempunyai keaktifan menggigit pada malam hari terutama pada kaum laki-laki yang biasanya keluar malam untuk jaga malam. Nyamuk Anopheles sp paling aktif mencari darah pukul 21.00-03.00 dan kebiasaan penduduk menurut Purnama (2016) berada di luar rumah pada malam hari antara pukul 21.00 s/d 22.00 berhubungan erat dengan kejadian malaria, karena frekuensi menghisap darah jam tersebut tinggi terutama pada kaum laki - laki yang berada di luar rumah untuk jaga malam. Dalam penelitian ini tidak dilakukan analisis hubungan sehingga tidak diketahui faktor apa saja yang menyebabkan lebih tingginya kasus malaria pada wanita (Pamela, 2009).

Berdasarkan tempat tinggal penderita malaria di Kampung Nolokla Distrik Sentani Timur tahun 2019 yang tercatat di register Puskesmas Harapan yang tertinggi pada RW 3 yaitu 110 orang (37,9\%). Kondisi lingkungan yang terlihat di RW 3 adanya lingkungan fisik luar rumah yang kurang dijaga kebersihannya seperti adanya semak-semak, rawa-rawa, selokan, barang bekas dan genangan air seperti bekas injakan kaki dan injakan ban sehingga berpotensi menjadi tempat perindukan larva Anopheles $s p$ dan meningkatkan kejadian malaria.

Waktu kejadian malaria di Kampung Nolokla Distrik Sentani Timur pada bulan Januari tercatat 65 orang $(22,4 \%)$, bulan Februari yaitu 108 orang, dan Maret yaitu 117 orang (40,4\%). Hal ini menunjukkan bahwa setiap bulan mengalami peningkatan dan peningkatan paling tertinggi pada bulan Maret yaitu 117 orang (40,4\%). Kondisi yang terjadi di bulan Maret yaitu cuaca yang buruk, seperti hujan terus menerus diselingi panas. Curah hujan yang tidak teratur akan menyebabkan terbentuknya tempat perindukan nyamuk Anopheles $s p$ dan hujan yang diselingi panas akan memperbesar kemungkinan berkembang biak nyamuk Anopheles sap (Pamela, 2009).

Peta distribusi spasial penderita malaria memperlihatkan pada bulan Februari hingga Maret pada RW 1 yaitu 17 titik penderita malaria, RW 2 yaitu 13 titik penderita malaria, RW 3 yaitu 37 titik penderita malaria, RW 4 yaitu 17 titik penderita malaria dan RW 5 yaitu 14 titik penderita malaria. Hal ini menunjukkan bahwa sebagian besar penderita malaria yang terletak di RW 3 dengan jumlah titik penderita malaria sebanyak 37 orang. Di mana letak rumah penderita sebagian besar berada di pinggiran hutan, halaman rumah terdapat rawarawa dan terdapat kubangan, dan genangan air seperti bekas injakan kaki hewan dan injakan ban, juga selokan dan lingkungan fisik luar rumah yang kurang dijaga kebersihannya seperti barang bekas yang di buang di depan rumah dengan sembarangan sehingga berpotensi menjadi tempat perindukan larva Anopheles sp (Sunaryo \& Benedictus ,2012).
Habitat larva nyamuk Anopheles punctulatus antara lain berupa bekas roda kendaraan, pijakan kaki hewan besar, aliran sungai, aliran sungai dengan vegetasi air, tepian sungai, kubangan sementara, kolam buatan, saluran irigasi, vegetasi algae, pelepah sagu, tempurung kelapa, lubang-lubang pohon, selokan dan pelepah pisang. Sedangkan larva Anopheles farauti ditemukan di selokan, kubangan air, kolam kangkung dan kolam ikan serta di sumur. Habitat Anopheles koliensis ditemukan pada genangan air bekas pijakan hewan, kubangan babi, juga terdapat di selokan dan sumur yang terkena paparan sinar matahari langsung. Berdasarkan paparan tersebut, maka hasil penelitian ini sejalan dengan penelitian terdahulu, karena larva Anopheles sp ditemukan di Kampung Nolokla berupa kubangan dan bekas injakan ban kendaraan, namun yang membedakan, pada penelitian ini terdapat larva Anopheles sp yang hidup pada barang bekas, di mana pada barang bekas tersebut terdapat sedikit genangan air yang bercampur dengan tanah (Sandy.S,2015), walaupun pada penelitian Wardah dkk (2017), ditemukan bahwa tidak ada hubungan signifikan antara keberadaan breeding place dengan kejadian malaria, namun hal ini tidak mengurangi kewaspadaan terhadap kondisi lingkungan rumah agar tidak dijadikan sebagai breeding place bagi nyamuk Anopheles sp.. Hasil penelitian lain yang dilakukan oleh Puspaningrum, dkk (2016) menemukan bahwa seseorang yang tinggal di dekat genangan air memiliki risiko terkena malaria sebesar 2,692 kali dibandingkan dengan orang yang tidak tinggal dekat dengan genangan air.

\section{KESIMPULAN}

Distribusi penderita malaria tertinggi berdasarkan kelompok umur pada kelompok umur 15-64 tahun $(52,1 \%)$, berdasarkan jenis kelamin pada perempuan (53\%), berdasarkan tempat tinggal di RW 3 (37,9\%), berdasarkan waktu kejadian penularan malaria tertinggi pada bulan Maret $(40,4 \%)$.

Peta distribusi spasial epidemiologi penderita malaria di Kampung Nolokla Distrik Sentani Timur, penderita malaria tertinggi bertempat tinggal di RW 3, di mana letak rumah penderita malaria berada di pinggiran hutan, rawa-rawa dan terdapat kubangan serta genangan air sehingga berpotensi menjadi tempat perindukan larva Anopheles sp.

\section{SARAN}

Penanganan malaria saat ini tidak dapat dilakukan secara terpisah antara faktor Host, Agent dan Environment, melainkan secara komprehensif untuk menekan laju penularan malaria, mengingat Papua adalah daerah endemik malaria dan sebagai penyumbang kasus terbesar di Indonesia, ditambah lagi target eliminasi malaria Indonesia yang harus dicapai pada Tahun 2030.

Penelitian selanjutnya adalah mencari hubungan antara variabel, di antaranya distribusi spasial penderita 
malaria, keberadaan vektor malaria, keberadaan parasit malaria pada vektor, resistensi obat dan lokasi perindukan sehingga dapat diketahui letak permasalahan yang menentukan jenis intervensi yang paling tepat dalam upaya menurunkan kasus malaria di Papua khususnya dan di Indonesia pada umumnya.

\section{DAFTAR PUSTAKA}

Arsunan,A.A, 2012, Malaria di Indonesia Tinjauan Aspek Epidemiologi, Makassar: Masagena Press.

Balitbang Biomedis, 2015, Peta Anopheles di Tanah Papua, Jakarta: Lembaga Penerbit Balitbangkes.

Cahyati, \& Lukman. F, 2015, Arc View dan Epi Info. Semarang : Ikm Unes

Puspaningrum, D. T., Rahardjo, M., \& Nurjazuli, N. (2016). Analisis Spasial Pengaruh Faktor Lingkungan Terhadap Persebaran Kasus Malaria Di Kecamatan Punggelan Kabupaten Banjarnegara. Jurnal Kesehatan Masyarakat (Undip), 4(4), 882891.

Hastuty, H. S. B., \& Natalia, Y. F. (2020)., Distribusi Spasial Larva Anopheles sp di Wilayah Kerja Puskesmas Harapan Distrik Sentani Timur Kabupaten Jayapura. Gema Kesehatan, 12(1), 14-19

Hutrianto \& Syakti, F. (2019). Sistem Informasi Geografis Penderita Malaria pada Kelurahan Cereme Taba Kota Lubuklinggau. Digital Zone: Jurnal Teknologi Informasi dan Komunikasi, 10(2), 178-188.

Kemenkes RI. 2018. Situasi Malaria Terkini Tahun 2018. http://www.malaria.id/. (diakses pada 3 Januari 2019)

Pamela , A. A.,2009. Hubungan Kondisi Fisik Rumah Dan Lingkungan Sekitar Rumah Dengan Kejadian
Malaria Di Desa Ketosari Kecamatan Bener Kabupaten Purworejo, Skripsi, Universitas Muhammadiyah Surakarta, http://eprints.ums.ac.id/5961/1/J410050013.PDF. (diakses pada 7 November 2018)

Sandy, S. (2015). Karakteristik Habitat Anopheles punctulatus group sebagai Vektor Malaria di Papua, Jurnal Buski, Vol.5, No.3, 126-131.

Suwito, S., Hadi, U. K., Sigit, S. H., \& Sukowati, S. (2010). Hubungan iklim, kepadatan nyamuk Anopheles dan kejadian penyakit malaria. Jurnal Entomologi Indonesia, 7(1), 42-42. Sulasmi,Sri dkk, Pengaruh Curah Hujan, Kelembaban, dan Temperatur terhadap Prevalensi Malaria di Kabupaten tanah Bumbu Kalimantan Selatan, J.Health.Epidemiol.Commun.Dis.;3(I): 22-27.

Sunaryo dan Benedictus. 2012. Distribusi Spasial kasus Malaria di Kecamatan Pagedongan Kabupaten Banjarnegara Provinsi Jawa Tengah. Prosiding Seminar Nasional Kesehatan Jurusan Kesehatan Masyarakat FKIK Unsoed. Purwokerto.

Wardah, W., Nurjazuli, N., \& Dangiran, H. L. (2017). Analisis Spasial Faktor Lingkungan Dengan Kejadian Malaria Di Wilayah Kerja Puskesmas Salaman I, Kabupaten Magelang. Jurnal Kesehatan Masyarakat (e-Journal), 5(5), 911-919.

\section{UCAPAN TERIMAKASIH}

Terima kasih disampaikan kepada kepala Puskesmas Harapan dan penanggung jawab program malaria yang telah mendukung jalannya penelitian hingga penelitian ini dapat terselesaikan dengan baik 